\title{
Effects on duration of post-operative ischemia and patterns of blood flow recovery in different conditions of mouse hind limb ischemia
}

\author{
Vascular Cell 3:14 I DOI: 10.1186/2045-824X-3-14 ～～ＣＬi et al.; licensee Publiverse Online S.R.L. 2011 \\ Received: 7 Feb 2011 I Accepted: 14 Feb 2011 | Published: 14 Feb 2011 \\ Al-Mubarak Husain A, Alamri Talal M, Aljabab Saif A, Atteya Mohammad, Quan Adrian, Teoh Hwee, \\ Shukla Praphulla C, Verma Subodh, Aldahmash Abdullah, Aljabri Badr, Napoli Claudio, \\ Al-Omran Mohammed ${ }^{@}$ \\ ${ }^{+}$Contributed equally ${ }^{@}$ Corresponding author
}

\begin{abstract}
Background

Current limitations to the experimentation on patients with peripheral arterial disease push the development of different preclinical strategies. We investigated both duration of ischemia and blood flow recovery in mouse models of partial femoral artery ligation.
\end{abstract}

\section{Methods}

Male BALB/c mice were used. The ligation over needle method involved placing a suture needle over the femoral artery, ligating over it and then removing the needle. The transfixation method involved transfixing the approximate center of the femoral artery and then tying the suture. Laser Doppler Perfusion Imaging was used to assess perfusion every $3^{\text {rd }}$ day until 42 days after the procedure.

\section{Results}

Ligation over needle method: Immediately post procedure, mean perfusion was $-71.87 \% \pm 4.43$. Then mean difference in perfusion remained below the base line reading on days 3,6,9, and 12. From day 15 on wards mean perfusion progressively improved remaining near base line. Transfixation Method: Immediately post procedure mean perfusion was $-70.82 \% \pm 4.73$. Mean perfusion improved following the procedure on days 3 and 6 ; a plateau followed this on days 9, 12 and 15 . From day 15 onwards perfusion progres sively improved remaining well below base line until crossing it on day 36.

\section{Conclusion}

The currently described models do not pose major improvements over previously described methods.

\section{Keywords}

Hindlimb Ischemia - Angiogenesis - LDPI - Mouse Model - Peripheral Arterial Disease

\section{Introduction}

Peripheral arterial disease (PAD) is a clinical manifestation of atherosclerosis affecting the aorto-iliac and infrainguinal arterial trees. Intermittent claudication is the classical symptom of PAD [ 1, 2]; patients may be asymptomatic or present with non-healing ulcers and tissue loss. More relevantly, PAD can also be considered as a marker of systemic atherosclerosis, as patients with PAD are at greater risk of having myocardial infarction [3] and ischemic stroke [4]. 
Translational approaches using mouse models of hind limb ischemia have advantages over other animal models. Mice require less food [ 5], housing space [ 6], and time to acquire Laser Doppler Perfusion Imaging scans as compared to other rodents.

In general, previously described mouse models of ischemia revolve around the same scheme [ 7- 11]. After exposure, the femoral artery of the hind limb is dissected free from the surrounding tissue. Then ligations are made at various points with or without removing part of the artery with or without the vein. The end result is complete obstruction of the blood supply to the limb. The abrupt and absolute nature of the ischemia induced by these methods is similar to what occurs in acute arterial occlusion. The objective of this study was to develop a murine model of surgically induced ischemia via partial femoral artery ligation that remains ischemic for a minimum period of 27 days.

\section{Methods and Results}

All procedures and protocols were approved by the Institutional Review Committee of The College of Medicine, King Saud University, Riyadh, Saudi Arabia. Animal experiments were performed at the animal housing facilities of The College of Medicine, King Saud University, Riyadh, Saudi Arabia. Male BALB/c mice aged between 11-12 weeks and weighing 23-34 g were used. The animals were anesthetized with Ketamine-Xylazine intraperitonially (IP) for the surgical procedures and for the laser Doppler measurements of limb perfusion.

Laser Doppler perfusion imaging (LDPI) (Perimed, PIM 3) was used to evaluate the perfusion over the course of 6 weeks postoperatively. The mice were placed on a $37^{\circ} \mathrm{C}$ warming pad, positioned using an alignment triangle and placed between a Styrofoam barrier (See Figure 1). LDPI was used to record perfusion of hind limbs preoperatively, immediately postoperatively (D0) and on every third day following D0. The dimensions of the scanned area and its resolution were kept constant during the entire scanning period, as was the distance of the laser Doppler head from the scanning surface. Serial measurements were obtained over the same region of interest using anatomical landmarks. Analysis was performed by calculating the mean perfusion for both ischemic and non-ischemic limbs from the color coded images. The change in perfusion was expressed as the percentage change between the right (ischemic) to the left (normal, reference) limb. Mice that did not have decrease from baseline measurements immediately post-operatively or on day 3 were excluded from the study. They were considered unsuccessful procedures. Figure 1

Positioning and setting used when taking LDPI scans (1), Anatomical landmarks used for determining Regions of interest (2).

On day 42 of the study, the mice were euthanized with an overdose of anesthetic and cervical dislocation after performing LDPI scans. Histological experiments were done at The Stem Cell Unit, Department of Anatomy, College of Medicine, King Saud University, Riyadh, Saudi Arabia. Samples of skeletal muscle were taken from the calf and thigh of both limbs and placed in $10 \%$ formaldehyde till processing. After fixation in paraffin wax, histological sections $5 \mu \mathrm{m}$ thick were stained with Hematoxylin and Eosin stains and were examined under a light microscope. Skin samples from the medial aspect of both limbs we re placed in $10 \%$ formaldehyde until fixation in paraffin blocks. The surgical procedures were performed on the right hind limb. Exposure of the femoral artery was obtained by a skin incision parallel to the inguinal ligament approximately the width of the thigh. After dissecting the proximal portion femoral artery just distal to the inguinal ligament, one of two procedures was performed to induce unilateral hind limb ischemia.Results are presented as mean $\pm \mathrm{SE}$.

\section{Ligation over needle group}

The ligation over needle method involved placing a 10-0 suture needle (Ethicon) and ligating over it with a 9-0 prolene (Ethicon) suture thread tying it 4 times followed by removing the needle. A total of fourteen mice were recruited in the ligation over needle group. Two mice were excluded immediately postoperatively, one mouse died from anesthesia while performing the procedure and four mice were excluded day three postoperatively. A total of seven mice were included in this study group (Procedure success rate 50\%). One mouse was found dead (unknown cause) on day six. One mouse was found dead on day nine (injury from other mouse in cage). One mouse escaped on day twenty-four. A total of four mice completed follow up until day 42 after the procedure. The base line mean perfusion was $-7.35 \% \pm 1.85$. Immediately post procedure mean perfusion was $-71.87 \% \pm 4.43$. Then mean difference in perfusion remained below the base line reading on days 3, 6, 9, and $12(-57.63 \% \pm 9.28,-41.08 \% \pm$ $11.75,-35.92 \% \pm 16.97$ and $20.38 \% \pm 8.99$ respectively). From day 15 on wards mean perfusion progressively improved remaining near base line. A series of LDPI scans from this group are presented in Figure 2A. The mean differences in perfusion between the right (ischemic) and the left (normal) plotted against time are shown in Figure 2B. Light microscopic examination of tissue sections from the right calf muscle showed loss of muscle fibers and replacement with fibrosis and adipose tissue, congested vessels were also seen; all other tissue sections did not have any abnormalities (see Figure 2C). 

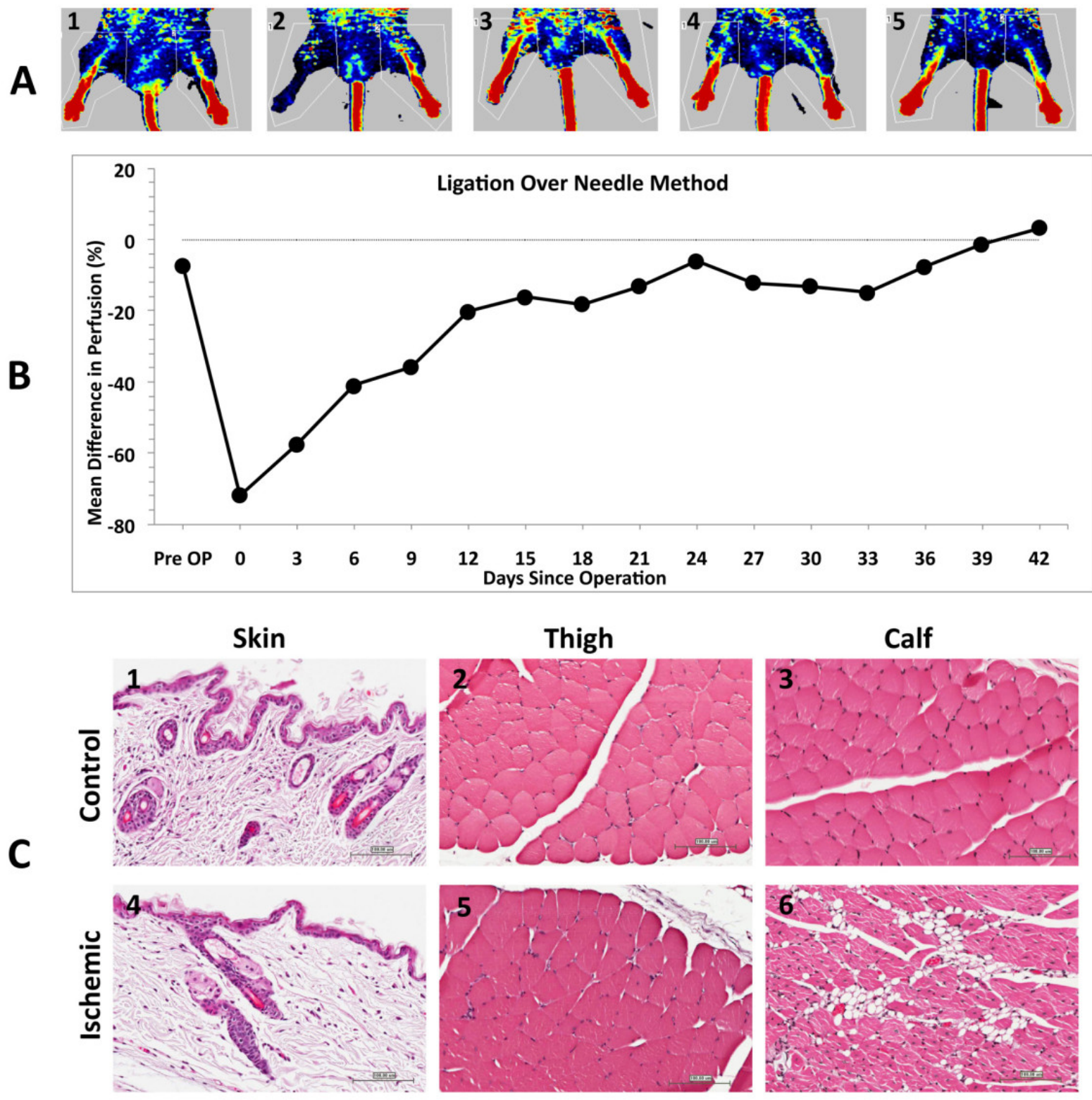

2A; Laser Doppler perfusion Images, Ligation over needle group; Pre-operative, Post-Operative, Day 12, Day 24 and Day 42 post ischemia (1,2,3,4 and 5 respectively). Figure 2B; Mean difference in perfusion (\%), Ligation over needle group. Figure 2C; Skin from medial aspect of left thigh with normal appearance of dermis, epidermis and skin appendages (1); Left thigh with normal appearance of skeletal muscle fibers (2); Left calf with normal appearance of skeletal muscle fibers (3); Skin from medial aspect of right thigh with normal appearance of dermis, epidermis and skin appendages (4); Right thigh with normal appearance of skeletal muscle fibers (5); Right calf with vascular congestion, damage to some skeletal muscle fibers and replacement by adipose tissue (6). All sections were taken at 200x, stained with Hematoxylin and Eosin stain. Scale bars are $100 \mu \mathrm{m}$.

\section{Transfixation group}

The transfixation method was performed by flattening the femoral artery with micro forceps followed by transfixating the approximate center with 9-0 prolene (Ethicon) and then tying it 4 times. A total of twelve mice were recruited in the transfixation group. Two mice were excluded immediately postoperatively, one mouse died during the procedure from anesthetic causes and three mice were excluded on day 3. A total of six mice were included in this group (procedure success rate 50\%). One mouse was found dead due to (unknown cause) on day twenty-one. One mouse died from anesthetic complications on day thirty-three. A total of four mice completed 
follow up until day 42 after the procedure. The base line mean perfusion was $4.65 \% \pm 4.05$. Immediately post procedure mean perfusion was $-70.82 \% \pm 4.73$. Mean perfusion improved following the procedure on days 3 and 6 $(-62.95 \% \pm 8.85$ and $-44.5 \% \pm 12.38$ respectively) and was followed by a plateau on days 9,12 and $15(-39.82 \% \pm$ $12.23,-39.2 \% \pm 10.71$ and $-39.1 \% \pm 9.23$ respectively). From day 15 onwards perfusion progressively improved remaining well below base line until crossing it on day $36(-26.42 \% \pm 12.05,-19.48 \% \pm 7.80,-20.08 \% \pm 15.46$, $-26.24 \% \pm 15.12,-10.46 \% \pm 12.88,-24.48 \% \pm 2.59$ and $2.82 \% \pm 4.86$ on days $15,18,2124,27,30,33$ and 36 respectively). A series of LDPI from this group are presented in Figure 3A. The mean differences in perfusion between the right (ischemic) and the left (normal) plotted against time are shown in Figure 3B . Light microscopic examination of tissue sections of skin from the right limb showed congested blood vessels and mild inflammatory cellular infiltrate (neutrophils, eosinophils and macrophages) in the upper dermis. Sections from the right calf had loss of muscle fibers and replacement by fibrosis and adipose tissue. All other sections did not have any abnormalities (see Figure 3C).

Figure 3

A
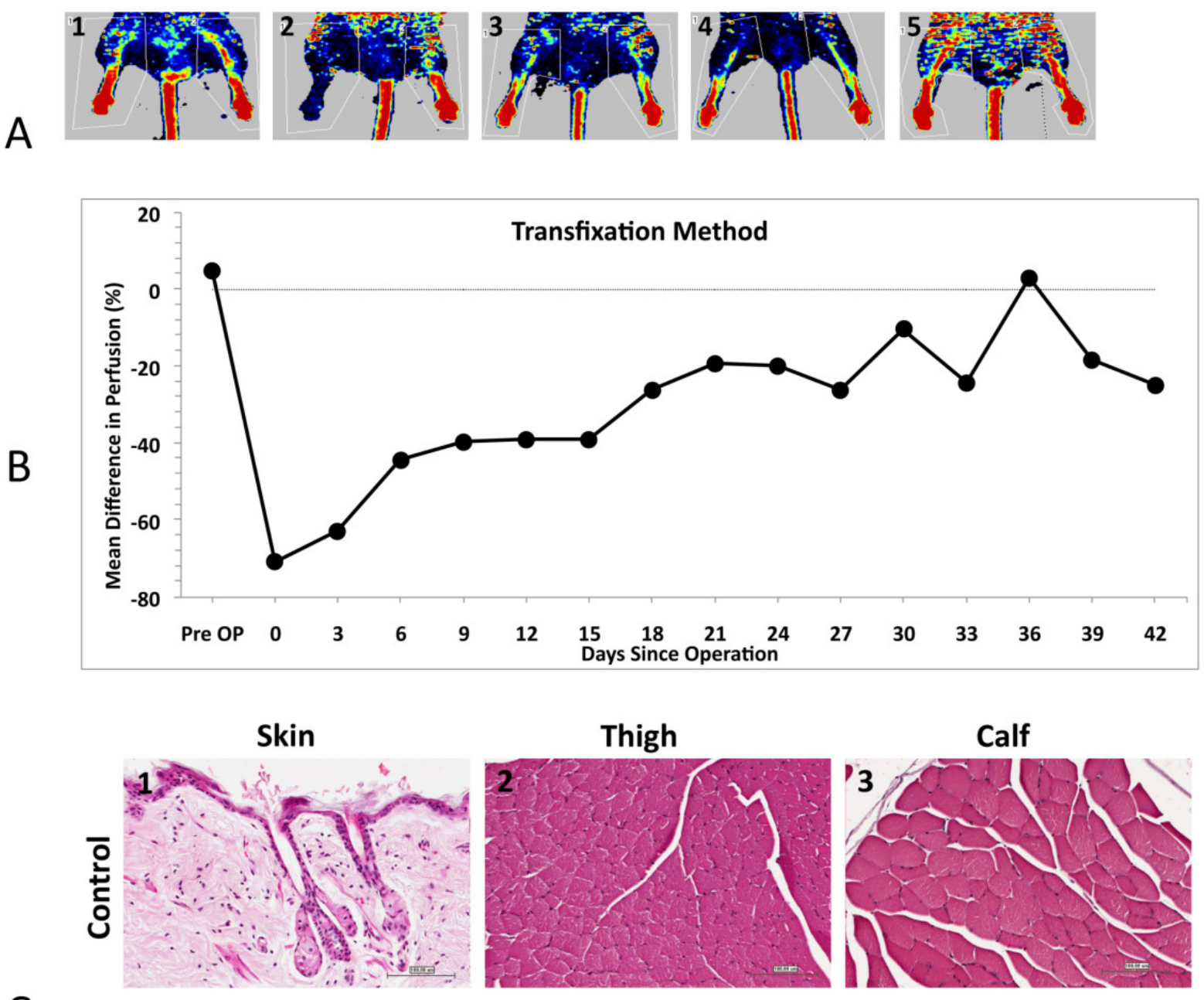

C
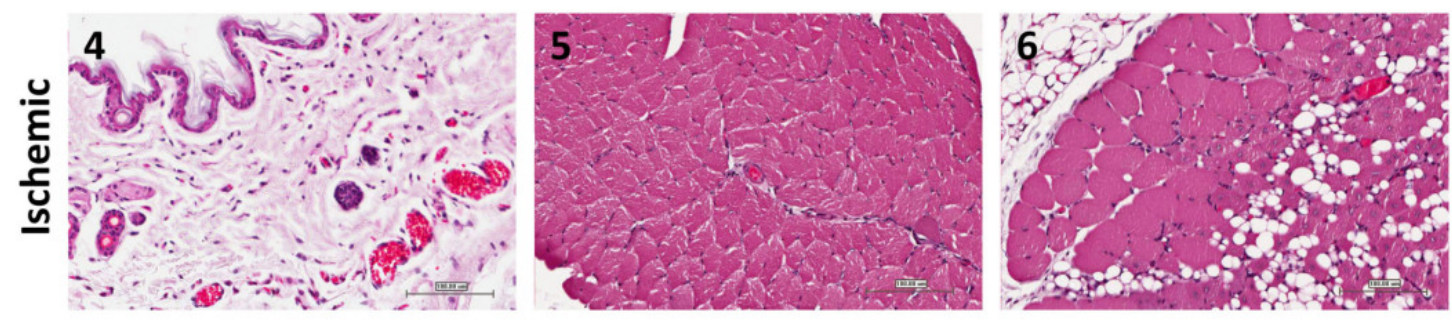
Day 42 post ischemia (1,2,3,4 and 5 respectively). 3B; Mean Difference in perfusion, Transfixation group. Figure 3C; Skin from medial aspect of left thigh with normal appearance of dermis, epidermis and skin appendages (1); Left thigh with normal appearance of skeletal muscle fibers (2); Left calf with normal appearance of skeletal muscle fibers (3); Skin from medial aspect of right thigh with mild vascular congestion and mild inflammatory cellular infiltration (4); Right thigh with normal appearance of skeletal mu scle fibers (5); Right calf with vascular congestion, damage to some skeletal muscle fibers and replacement by adipose tissue (6). All sections were taken at $200 \times$, stained with Hematoxylin and Eosin stain. Scale bars are $100 \mu \mathrm{m}$.

\section{Discussion}

The major findings of our paper are: 1) recovery pattern of ischemia is independent of initial postoperative decrease in perfusion and 2) calf muscle is the sample of choice for obtaining representative results. The limitations of our study include: 1) relatively low success rate, $50 \%$ in both methods and 2) limited number of mice that completed the study duration, $\mathrm{n}=4$.

Previously described models of ischemia completely impede blood flow [ 7-11], causing an acute ischemic episode. Variations seen between the different methods employed include: use of suture material or electro-cautery [12], inclusion of the accompanying vein [ 13-15] and extent of excision which ranges from the external iliac artery to the popliteal vessels [ 16-23]. The end result of using such procedures results in an immediate post procedure drop in perfusion ranging from $-90 \%$ to $-75 \%$ and a perfusion ranging from - 5\% to - $60 \%$ twenty eight days after the procedure [ 13-20]. The post procedure decrease in perfusion of the ligation over needle and transfixation methods is comparable $(-71.87 \%$ and $-70.82 \%$, respectively) to previously described methods. However, when the perfusion on the $27^{\text {th }}$ day after the procedure is well above what can be achieved in previously described methods $(-12.25 \%$ and $-26.24 \%$, ligation over needle and transfixation methods respectively).

In conclusion, both methods described were successful in inducing ischemia. The major differences between them is the duration of the ischemia postoperatively and the pattern of recovery. The optimum area to obtain skeletal muscle samples is from the calf. The currently described models do not pose major improvements over previously described methods.

\section{Declarations}

\section{Acknowledgements}

We thank the international scientist exchange program promoted by postgraduate and continuing medical education of King Saud University, Riyadh, Kingdom of Saud Arabia.

\section{Authors' original submitted files for images}

Below are the links to the authors' original submitted files for images.

Authors' original file for figure 1

Authors' original file for figure 2

Authors' original file for figure 3

\section{Competing interests}

The authors declare that they have no competing interests.

\section{Authors' contributions}

HA, TA and SA participated in the design, animal work, sample collection and writing of the manuscript. MAt participated in the preparation of the histological samples and data analysis. AQ, HT and PS participated in the design, data analysis and writing of the manuscript. SV, AA, BA, CN and MAl participated in the design, data interpretation and critical appraisal of the manuscript. All authors read and approved the final manuscript.

\section{References}

1. Rose GA. The diagnosis of ischemic heart pain and intermittent claudication in field surveys. BullWorld Health Organ. 1962;27:645-658. 
2. The global burden of disease: 2004 update. World Health Organization. 2008

3. Criqui MH, Langer RD, Fronek A, Feigelson HS, Klauber MR, McCann TJ, Browner D. Mortality over a period of 10 years in patients with peripheral arterial disease. N Engl J Med. 1992;326:381-386.

View Article Google Scholar

4. Wilterdink JL, Easton JD. Vascular event rates in patients with atherosclerotic cerebrovascular disease. Arch Neurol. 1992;49:857-63.

View Article Google Scholar

5. . . Nutrient Requirements of Laboratory Animals Fourth Revised Edition. 1995;:-.

View Article Google Scholar

6. . . Guide for the Care and Use of Laboratory Animals. 1996;:- .

View Article Google Scholar

7. Moon MH, Kim SY, Kim YJ, Kim SJ, Bae YC, Sung SM, Jung JS. Human adipose tissue-derived mesnchymal stem cells improve postnatal neovascularization in mouse model of hindlimb ischemia. Cell Physiol Biochem. 2006;17:279-290.

View Article Google Scholar

8. Goto T, Fukuyama N, Aki A, Kanabuchi K, Kimura K, Taira H, Tanaka E, Wakana N, Mori H, Inoue H. Search for appropriate experimental methods to create stable hind-limb ischemia in mouse. Tokai J Exp Clin Med. 2006;31:128-132.

View Article Google Scholar

9. Couffinhal T Silver M Zheng LP Keamey M Witzenbichler B Isner JM Mouse model of angiogenesis Am J Pathol 1998152166716791858441

10. Miranville A, Heeschen C, Sengenès C, Curat CA, Busse R, Bouloumié A. Improvement of postnatal neovascularization by human adipose tissue-derived stem cells. Circulation. 2004;110:349-355.

View Article Google Scholar

11. Napoli C Williams-Ignarro S de Nigris F de Rosa G Lerman LO Farzati B Matarazzo A Sica G Botti C Fiore A Byrns RE Sumi D Sica V Ignarro LJ Beneficial effects of concurrent autologous bone marrow cell therapy and metabolic intervention in ischemia-induced angiogenesis in the mouse hindlimb Proc Natl Acad Sci USA 200510217202 172061288005 10.1073/pnas.0508534102

12. Gianella A, Guerrini U, Tilenni M, Sironi L, Milano G, Nobili E, Vaga S, Capogrossi MC, Tremoli E, Pesce M. Magnetic resonance imaging of human endothelial progenitors reveals opposite effects on vascular and muscle regeneration into ischaemic tissues. Cardiovasc Res. 2010;85:503-513.

View Article Google Scholar

13. Ohashi K Ouchi N Sato K Higuchi A Ishikawa TO Herschman HR Kihara S Walsh K Adiponectin promotes revascularization of ischemic muscle through a cyclooxygenase 2-dependent mechanism Mol Cell Biol 200929348734992698754 10.1128/MCB.00126-09

14. Bir SC, Esaki J, Marui A, Sakaguchi H, Kevil CG, Ikeda T, Komeda M, Tabata Y, Sakata R. Therapeutic Treatment with Sustained-Release Platelet-Rich Plasma Restores Blood Perfusion by Augmenting Ischemia-Induced Angiogenesis and Arteriogenesis in Diabetic Mice. J Vasc Res. 2010;48:195-205. View Article Google Scholar

15. Ohashi K Ouchi N Higuchi A Shaw RJ Walsh K LKB1 deficiency in Tie2-Cre-expressing cells impairs ischemia-induced angiogenesis J Biol Chem 201028522291222982903404 10.1074/jbc.M110.123794

16. Park B Hoffman A Yang Y Yan J Tie G Bagshahi H Nowicki PT Messina LM Endothelial nitric oxide synthase affects both early and late collateral arterial adaptation and blood flow recovery after induction of hind limb ischemia in mice J Vasc Surg 2010511651732815245

10.1016/j.jvs.2009.08.045 
17. Bhang SH, Cho SW, Lim JM, Kang JM, Lee TJ, Yang HS, Song YS, Park MH, Kim HS, Yoo KJ, Jang Y, Langer R, Anderson DG, Kim BS. Locally delivered growth factor enhances the angiogenic efficacy of adipose-derived stromal cells transplanted to ischemic limbs. Stem Cells. 2009;27:1976-1986.

View Article Google Scholar

18. Tokudome T, Kishimoto I, Yamahara K, Osaki T, Minamino N, Horio T, Sawai K, Kawano Y, Miyazato M, Sata M, Kohno M, Nakao K, Kangawa K. Impaired recovery of blood flow after hind-limb ischemia in mice lacking guanylyl cyclase-A, a receptor for atrial and brain natriuretic peptides. Arterioscler Thromb Vasc Biol. 2009;29:1516-1521.

View Article Google Scholar

19. Yan J Tie G Park B Yan Y Nowicki PT Messina LM Recovery from hind limb ischemia is less effective in type 2 than in type 1 diabetic mice: roles of endothelial nitric oxide synthase and endothelial progenitor cells J Vasc Surg 2009501412 14222797079 10.1016/j.jvs.2009.08.007

20. Kato S, Amano H, Ito Y, Eshima K, Aoyama N, Tamaki H, Sakagami H, Satoh Y, Izumi T, Majima M. Effect of erythropoietin on angiogenesis with the increased adhesion of platelets to the microvessels in the hind-limb ischemia model in mice. J Pharmacol Sci. 2010;112:167-175.

View Article Google Scholar

21. Lian Q, Zhang Y, Zhang J, Zhang HK, Wu X, Zhang Y, Lam FF, Kang S, Xia JC, Lai WH, Au KW, Chow YY, Siu CW, Lee CN, Tse HF. Functional mesenchymal stem cells derived from human induced pluripotent stem cells attenuate limb ischemia in mice. Circulation. 2010;121:1113-1123.

View Article Google Scholar

22. Leifheit-Nestler M, Conrad G, Heida NM, Limbourg A, Limbourg FP, Seidler T, Schroeter MR, Hasenfuss G, Konstantinides S, Schäfer K. Overexpression of integrin beta 5 enhances the paracrine properties of circulating angiogenic cells via Src kinase-mediated activation of STAT3. Arterioscler Thromb Vasc Biol. 2010;30:1398-1406.

View Article Google Scholar

23. Huang PH, Tsai HY, Wang CH, Chen YH, Chen JS, Lin FY, Lin CP, Wu TC, Sata M, Chen JW, Lin SJ. Moderate intake of red wine improves ischemia-induced neovascularization in diabetic mice--roles of endothelial progenitor cells and nitric oxide. Atherosclerosis. 2010;212:426-435.

View Article Google Scholar 